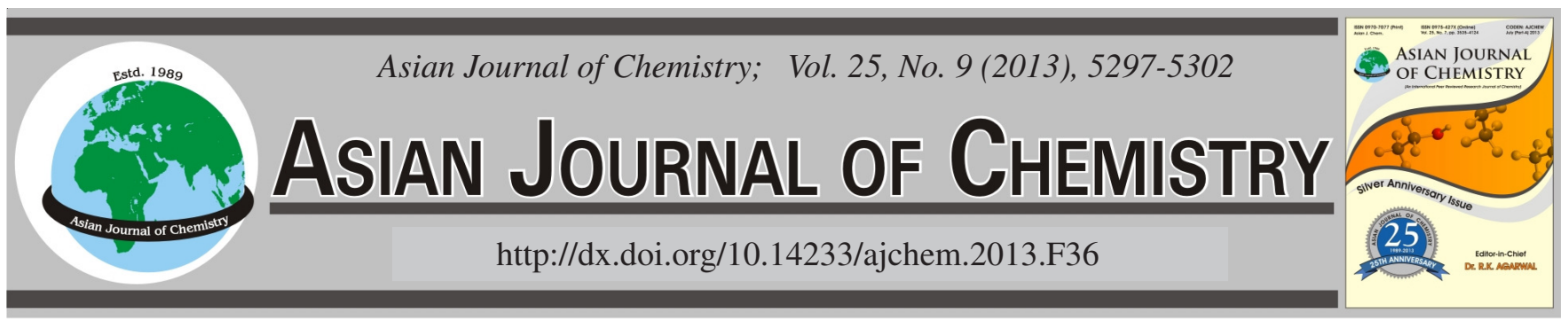

\title{
Effects of Various High $\alpha$-Olefins on the Terpolymerization with Metallocene Catalyst and Cocatalyst System $\dagger$
}

\author{
T.W. KIM ${ }^{1}$, U.R. CHO ${ }^{2}$ and D.H. KIM ${ }^{1, *}$
}

${ }^{1}$ Convergent Technology R \& D Division, Korea Institute of Industrial Technology, Ansan-si, Republic of Korea

${ }^{2}$ Korea University of Technology and Education, Cheoan-si, Republic of Korea

*Corresponding author: Fax: +82 31 80406239; Tel: +82 31 80406226; E-mail: dhkim@ kitech.re.kr

AJC-13191

Terpolymers composed of ethylene, high $\alpha$-olefin and $p$-methyl styrene using a rac-Et(Ind $)_{2} \mathrm{ZrCl}_{2}$ catalyst and cocatalyst system were synthesized. The terpolymers obtained were characterized by ${ }^{1} \mathrm{H}$ NMR and ${ }^{13} \mathrm{C}$ NMR spectroscopy. The catalytic activity, molecular weight, molecular weight distribution and compositions of the polymers were analyzed. The thermal properties of the polymers were investigated. The crystallinity of the terpolymers was determined by differential scanning calorimetry and wide-angle X-ray scattering. The catalytic activity increased to some degree with increasing chain length of the high a-olefin in the terpolymers. The crystallinity, mechanical and thermal properties decreased with increasing chain length of high $\alpha$-olefins in the terpolymers.

Key Words: Polyolefins, Elastomers, Catalyst, High $\alpha$-olefin, Terpolymerization.

\section{INTRODUCTION}

Metallocene catalysts, which were applicable to the polymerization process conditions of the Ziegler-Natta system were developed to precisely design the micromolecular structure and control the copolymerization reactivity. Research into polymerization using metallocene catalysts began with an identification of the structure of ferrocene by Wilkins and Fischer in 1952 and was developed further by Kaminsky in the 1980s. Copolymerization using metallocene catalysts, preparing polymers with narrow molecular weight distributions, high stereo-regularity and uniform comonomer incorporation are much easier than when a conventional Zeigler-Natta catalyst is used. Therefore, many studies have examined coordination polymerization using metallocene catalysts.

A metallocene catalyst is called a single-site catalyst because it carries a single active site, which is unlike existing commercial Ziegler-Natta catalysts. For this reason, the polymers produced with metallocene catalysts exhibit high tacticity, have a narrow distribution of molecular weights and allow easy comonomer insertion ${ }^{1-5}$.

On the other hand, previous studies focused mainly on copolymerization with little attention paid to terpolymerization ${ }^{6-15}$.

In this study, terpolymers were prepared and the effects of the chain length of the comonomer on the catalytic activity, thermal and mechanical properties of the terpolymers were studied.

\section{EXPERIMENTAL}

All manipulations were carried out in an inert nitrogen atmosphere. A glove box was used when handling the catalyst susceptible to moisture. High purity grade nitrogen gas (Dae-myung Gas Co.) was used after passing it through a molecular sieve (4 ̊)/manganese (II) oxide column. High purity grade ethylene gas (Dae-myung Gas Co.) was used after passing it through an alumina and zeolite column. 1-Hexene (Aldrich, $97 \%$ ), 1-octene (Aldrich, $94 \%$ ), 1-decene (Aldrich, $94 \%$ ), 1-dodecene (Aldrich, $95 \%$ ), toluene (Dae-myung, $99.5 \%$ ) and $n$-hexane (Dae-myung, $99.5 \%$ ) were purified by heating them over sodium under reflux using benzophenone as the indicator. $p$-Methyl styrene ( $p$-MS) was distilled under reduced pressure in the presence of $\mathrm{CaH}_{2}$ after performing a standard purification procedure.

Some calculated amounts of $\mathrm{rac}$-Et(Ind) $\mathrm{ZrCl}_{2}$ (Sigma Aldrich) and trityl tetrakis(pentafluorophenyl)borate (BORATE) (ACROS) were dissolved in toluene. The specimens for thermal, mechanical and wide-angle X-ray scattering (WAXS) analysis were prepared by compression molding using a hot press.

Typically, all the polymerization reactions were carried out in a $300 \mathrm{~mL}$ stainless steel autoclave with a mechanical stirrer. Polymerization was carried out at a fixed pressure of ethylene gas and $50^{\circ} \mathrm{C}$. After adding toluene, high $\alpha$-olefin and $p$-methyl 


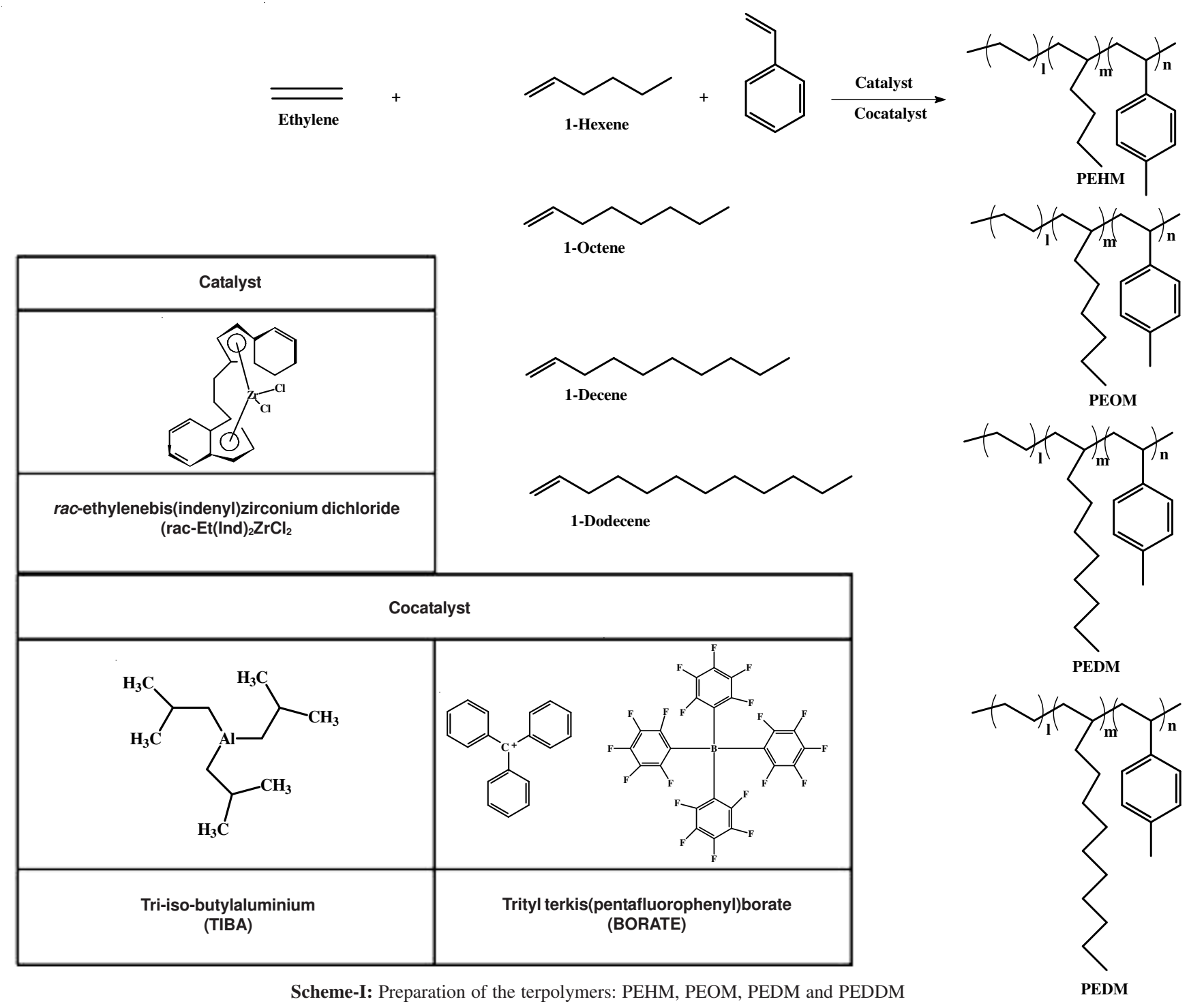

styrene, polymerization was initiated by injecting a solution of the catalyst and cocatalyst. After several minutes, the polymer solution was poured into a diluted $\mathrm{HCl} / \mathrm{EtOH}$ solution. The resulting polymer was washed with $\mathrm{EtOH}$ and dried in vacuo. Using a Soxhlet apparatus and $n$-hexane as a solvent, each soluble terpolymer was separated from the insoluble polyethylene (a type of by-product). Pure terpolymer, which was completely soluble in common organic solvents, such as hexane, toluene and tetrahydrofuran, was obtained after drying the soluble fractions.

The ${ }^{13} \mathrm{C}$ NMR spectra were obtained at $60{ }^{\circ} \mathrm{C}$ using a Bruker AVANCE $500 \mathrm{MHz}$ machine. Sample solutions of the terpolymers were prepared in $\mathrm{CDCl}_{3}$. The deuterated solvent was used to provide an internal lock signal. The ${ }^{1} \mathrm{H}$ NMR spectra were recorded on a Bruker AVANCE $500 \mathrm{MHz}$ machine with the NMR samples prepared in $\mathrm{CDCl}_{3}$ solvent.

The molecular weight and molecular weight distribution of the terpolymers were measured using a Polymer Laboratories Co. PL-GPC210 gel permeation chromatograph fitted with Styragel (olesis guard column) HT-type columns. The analyses were performed at $140{ }^{\circ} \mathrm{C}$ at a rate of $1.0 \mathrm{~mL} / \mathrm{min}$ with $1,2,4-$ trichlorobenzene as the solvent. Polystyrene with a well-known molecular weight was used as the standard.
Differential scanning calorimetry of the terpolymers was performed using a DSC7 machine (PERKIN ELMER Co.). The samples were heated from $0{ }^{\circ} \mathrm{C}$ to $150^{\circ} \mathrm{C}$ and cooled to 0 ${ }^{\circ} \mathrm{C}$ at a rate of $10^{\circ} \mathrm{C} / \mathrm{min}$. Subsequently, they were reheated at $10{ }^{\circ} \mathrm{C} / \mathrm{min}$ to $150{ }^{\circ} \mathrm{C}$. The crystallization temperature $\left(\mathrm{T}_{\mathrm{c}}\right)$, melting temperature $\left(\mathrm{T}_{\mathrm{m}}\right)$ and enthalpy of melting $\left(\Delta \mathrm{H}_{\mathrm{m}}\right)$ were derived from the second and third run curves. The measured $\Delta \mathrm{H}_{\mathrm{m}}$ value was converted to the degree of crystallinity $(1-\lambda)_{\Delta \mathrm{H}}$ using $290 \mathrm{~J} / \mathrm{g}$ as the enthalpy of melting of a perfect polyethylene crystal ${ }^{16}$.

The wide-angle X-ray scattering (WAXS, Rigaku D/ MAX-2200V) patterns were recorded in reflection mode at room temperature using a $\mathrm{Cu}$ radiation source at $40 \mathrm{kV}$ and $40 \mathrm{~mA}$. The diffraction scans were collected over a period of $20 \mathrm{~min}$ between 3.0 to $40.0^{\circ} 2 \theta$ and at a rate of $2 \% \mathrm{~min}$.

\section{RESULTS AND DISCUSSION}

Scheme-I presents the synthesis of terpolymers using a metallocene catalyst and cocatalyst system. rac-Et(Ind) ${ }_{2} \mathrm{ZrCl}_{2}$ was used as a metallocene catalyst. The $\mathrm{C}_{2}$-symmetric metallocene catalyst, rac-Et(Ind) ${ }_{2} \mathrm{ZrCl}_{2}$, has a relatively electron-rich indenyl ligand, which stabilizes the transition 
TABLE-1

SUMMARY OF THE POLYMERIZATION OF PE, PEHM, PEOM, PEDM AND PEDDM

\begin{tabular}{|c|c|c|c|c|c|c|c|c|c|c|c|c|}
\hline \multirow[b]{2}{*}{ Name $^{a}$} & \multicolumn{3}{|c|}{ Monomer (mol/L) } & \multirow[b]{2}{*}{$\begin{array}{c}\text { High } \\
\alpha \text {-olefin }\end{array}$} & \multirow[b]{2}{*}{$\begin{array}{c}\text { Yield } \\
(\mathrm{g})\end{array}$} & \multirow{2}{*}{$\begin{array}{l}\text { Catalytic } \\
\text { activity }^{\mathrm{c}}\end{array}$} & \multirow{2}{*}{$\begin{array}{c}\mathrm{M}_{\mathrm{w}}{ }^{\mathrm{d}}{ }^{-3} \\
\left(\times 10^{-3}\right)\end{array}$} & \multirow{2}{*}{$\begin{array}{c}\mathrm{M}_{\mathrm{n}}^{\mathrm{d}} \\
\left(\times 10^{-3}\right)\end{array}$} & \multirow[b]{2}{*}{$M^{\prime} D^{d}$} & \multicolumn{3}{|c|}{ Compositions $(\%)^{\mathrm{e}}$} \\
\hline & $\mathrm{E}^{\mathrm{b}}$ & $\begin{array}{c}\text { High } \\
\alpha \text {-olefin }\end{array}$ & $p$-MS & & & & & & & $E^{b}$ & $\begin{array}{c}\text { High } \\
\alpha \text {-olefin }\end{array}$ & $p$-MS \\
\hline $\mathrm{PE}$ & 0.4 & 0.8 & 0.2 & - & 3.20 & 2560 & - & - & - & 100 & - & - \\
\hline PEHM & 0.4 & 0.8 & 0.2 & 1-Hexene & 8.59 & 6872 & 155 & 50 & 3.1 & 83.9 & 14.9 & 1.2 \\
\hline PEOM & 0.4 & 0.8 & 0.2 & 1-Octene & 9.32 & 7456 & 155 & 48 & 3.2 & 84.1 & 15.3 & 0.6 \\
\hline PEDM & 0.4 & 0.8 & 0.2 & 1-Decene & 9.30 & 7440 & 155 & 49 & 3.0 & 85.3 & 13.7 & 1.0 \\
\hline PEDDM & 0.4 & 0.8 & 0.2 & 1-Dodecene & 8.40 & 6720 & 119 & 36 & 3.3 & 86.9 & 12.5 & 0.6 \\
\hline
\end{tabular}

${ }^{a}$ Polymerization conditions: ethylene $=0.4 \mathrm{~mol} / \mathrm{L}$, high $\alpha$-olefin $=0.8 \mathrm{~mol} / \mathrm{L}, p$-MS $=0.2 \mathrm{~mol} / \mathrm{L}$, catalyst $=2.5 \mu \mathrm{mol},[\mathrm{Al}] /[\mathrm{Zr}]: 1.5,30 \mathrm{~min}, 50{ }^{\circ} \mathrm{C}$ and toluene; ${ }^{b} \mathrm{E}=$ ethylene; ${ }^{\mathrm{c} C a t a l y t i c}$ activity $=\mathrm{kg}$ of polymer/(mol of catalyst $\left.\cdot \mathrm{h}\right) ;{ }^{\mathrm{d}}$ Determined by gel permeation chromatography $(\mathrm{GPC})$; ${ }^{\mathrm{e}}$ Determined by ${ }^{1} \mathrm{H}$ NMR spectroscopy

metal in the catalyst with cationic character, leading to higher catalytic activity. Trityl tetrakis(pentafluorophenyl)borate (BORATE) and tri-iso-butylaluminium (TIBA) was used as the cocatalyst. Four types of the terpolymers (PEHM, PEOM, PEDM and PEDDM) consisting of ethylene, high $\alpha$-olefins and $p$-methyl styrene ( $p$-MS) were prepared using the metallocene catalyst and cocatalyst system.

Table-1 lists the results of the terpolymerization with different high $\alpha$-olefins under identical polymerization conditions, such as catalyst contents, cocatalyst/catalyst molar ratio and the polymerization time and temperature.

The compositions of ethylene in the terpolymers increased with increasing chain length of the high $\alpha$-olefin in the terpolymers. This may be due to the low incorporation of high $\alpha$-olefins and $p$-methyl styrene in the terpolymers according to their steric effect, which made the ethylenic contents rich. The contents of $p$-methyl styrene in the terpolymers had little association with the chain length of the high $\alpha$-olefins in the terpolymers. The molecular weight of PEDDM was lower than that of the other terpolymers.

Fig. 1 shows the changes in the catalytic activity and polymer yield of the terpolymers and polyethylene. The catalytic activities and polymer yield of the terpolymers were higher than those of polyethylene. This was attributed to the positive comonomer effect: enhanced solubility of the terpolymers compared to that of the homopolymer (polyethylene), which favoured monomer diffusion to the active center, activation of new catalyst sites by the increased affinity for the metallocene catalyst and increased solubility of the monomer in the liquid phase due to the presence of a comonomer, which consequently led to an increased insertion rate ${ }^{17}$.

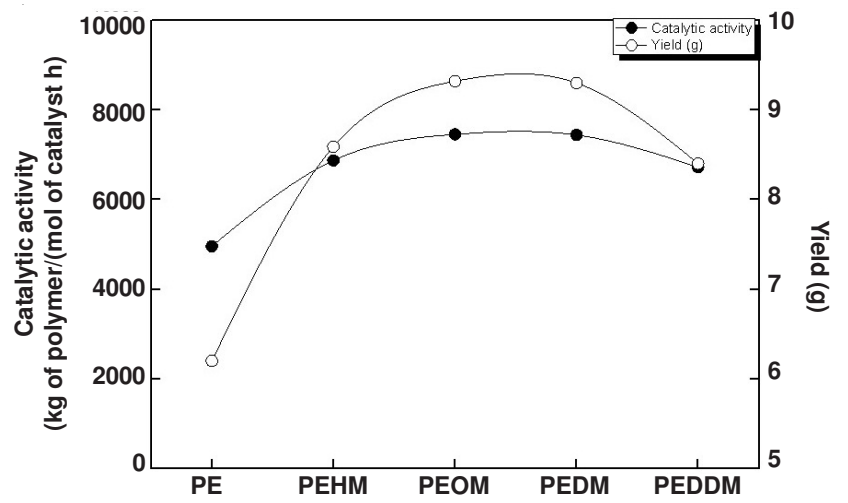

Fig. 1. Changes in the catalytic activity and polymer yield of the polymers: PE, PEHM, PEOM, PEDM and PEDDM
The catalytic activity increased with increasing chain length of the high $\alpha$-olefins until the maximum value of 7456 at PEOM was reached. Further increases in the chain length of the high $\alpha$-olefins resulted in a decrease in catalytic activity. Until the chain length of the high $\alpha$-olefins of the terpolymers reached the optical one, the high $\alpha$-olefins enhanced terpolymerization via the positive comonomer effect. On the other hand, when the chain length of the high $\alpha$-olefins exceeded the optical chain length, activation of this system was disturbed by the steric effect, which led to a decrease in catalytic activity.

Fig. 2 shows ${ }^{1} \mathrm{H}$ NMR spectra of the terpolymers. The peaks at 0.9 and $2.3 \mathrm{ppm}$ were assigned to the $\mathrm{CH}_{3}$ group of high $\alpha$-olefins and the $\mathrm{CH}_{3}$ group of $p$-methyl styrene, respectively. Compared to the peak for the $\mathrm{CH}_{3}$ group of $p$-methyl styrene, the peak of the high $\alpha$-olefins showed a relatively broad area. The $\mathrm{CH}_{2}$ peaks of ethylene and high $\alpha$-olefins were observed at 1-1.3 ppm. Multiple $\mathrm{CH}$ peaks of the aromatic ring in the $p$-methyl styrene were noted at approximately $7 \mathrm{ppm}$.

Fig. 3 shows the ${ }^{13} \mathrm{C}$ NMR spectra of the tepolymers. The $\mathrm{CH}$ peaks of the aromatic ring in the styrenic monomers of the terpolymers were confirmed at $125-130 \mathrm{ppm}$. All terpolymers examined showed similar spectra. The $\mathrm{CH}_{3}$ peak of the $p$-MS in the terpolymers was observed at $21 \mathrm{ppm}$.

Fig. 4 presents scanning electron microscopy (SEM) images of the terpolymers: PEHM, PEOM, PEDM and PEDDM. Considering the effect of the chain length of high $\alpha$ olefins on the morphology of the terpolymers, the crystalline structures of the obtained terpolymers appear to be lower with increasing chain length of high $\alpha$-olefins. The decrease in the crystallinity of the terpolymers along with the increasing chain length of high $\alpha$-olefins in the terpolymers is probably due to the increased steric hindrance caused by the introduction of high $\alpha$-olefins with a longer chain. This suggests that the chain length of high $\alpha$-olefins has an apparent effect on the morphology of the terpoloymers ${ }^{14}$.

Fig. 5 shows the wide angle X-ray scattering data for the terpolymers. As expected, there are three peaks in all samples. A broad amorphous peak was centered at approximately 19.5$20^{\circ}$. Previous studies assigned this peak to the side branches of high $\alpha$-olefin participating in the crystalline structure ${ }^{14}$. The other peaks at $21.8^{\circ}$ and $24.3^{\circ} 2 \theta$ were assigned to the characteristic orthorhombic cell of polyethylene ${ }^{18-20}$. The longer chain lengths of high $\alpha$-olefin in the terpolymers appear to disturb crystallization, which might be due to the increased steric hindrance. This leads to a decrease in the crystal peak intensity 


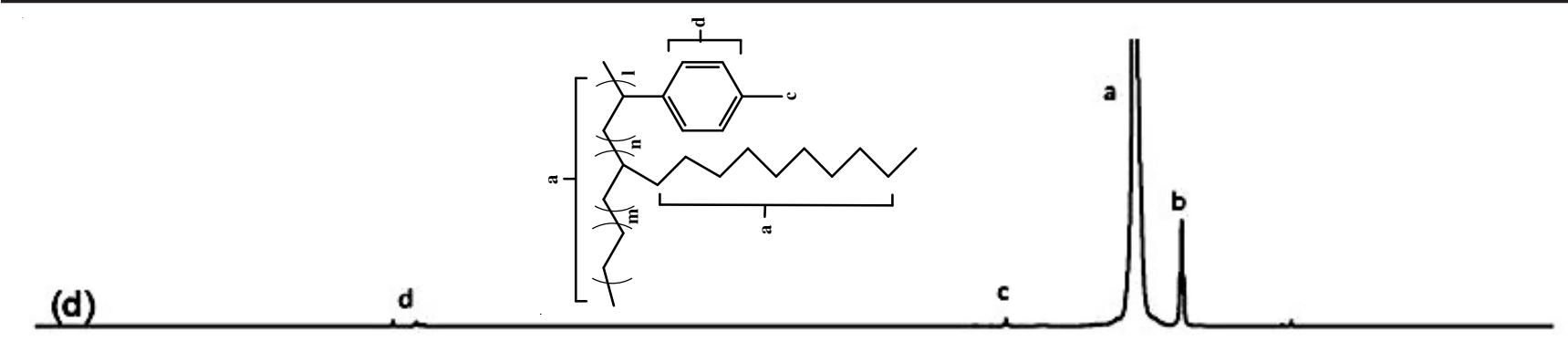

(c) d

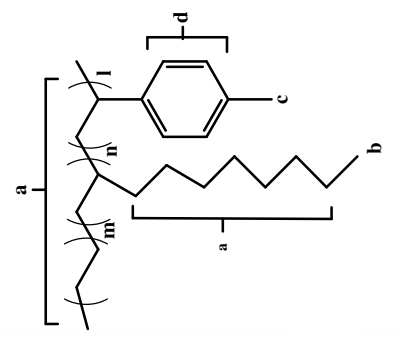

c

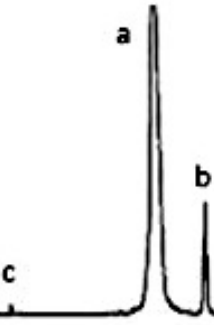

(b)
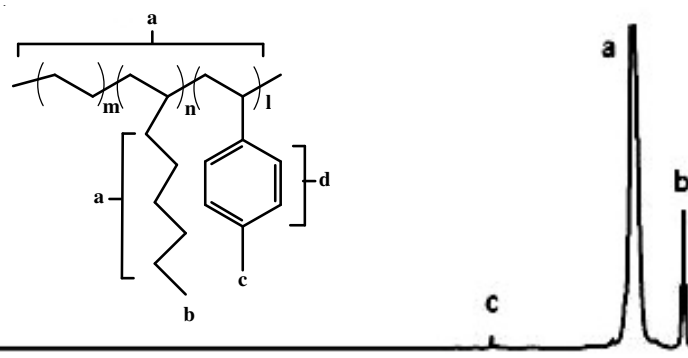

(a)

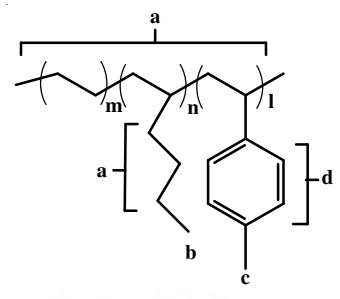

c

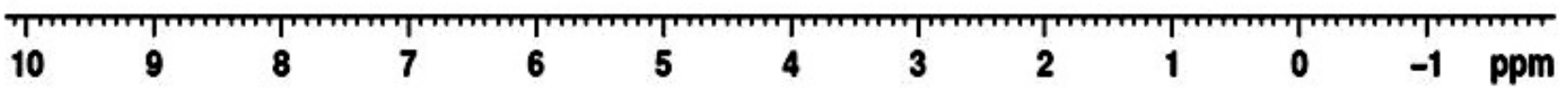

Fig. 2. ${ }^{1} \mathrm{H}$ NMR spectra of the terpolymers: (a) PEHM, (b) PEOM, (c) PEDM and (d) PEDDM

and an increase in the intensity of the amorphous peak. These results showed that the crystallinity is determined more by the chain length of high $\alpha$-olefin in the terpolymers than the ethylene contents.

Fig. 6 shows differential scanning calorimetry thermograms for the terpolymers and Table-2 lists the differential scanning calorimetry data. The $\mathrm{T}_{\mathrm{m}}$ increased with increasing chain length of high $\alpha$-olefins in the terpolymers until the maximum value of $80.5^{\circ} \mathrm{C}$ for PEDM was reached. On the other hand, in the case of PEDDM, which has the highest chain length, $\mathrm{T}_{\mathrm{m}}$ was lowest among the terpolymers. This was attributed to the lowest molecular weight and crystallinity of PEDDM compared to those of the other terpolymers.

\section{Conclusion}

Four types of the terpolymers consisting of ethylene, high $\alpha$-olefins and $p$-methyl styrene were prepared using a metallocene catalyst and co-catalyst system. The composition of ethylene in the terpolymers increased with increasing chain length of the high $\alpha$-olefin in the terpolymers. 
(d)

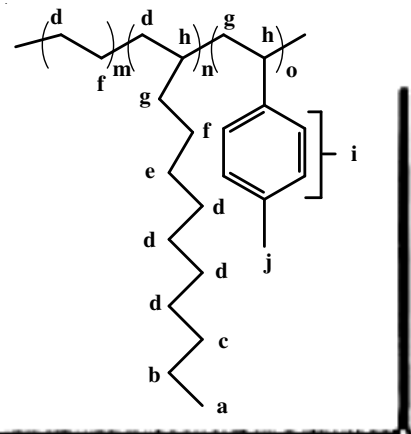
a

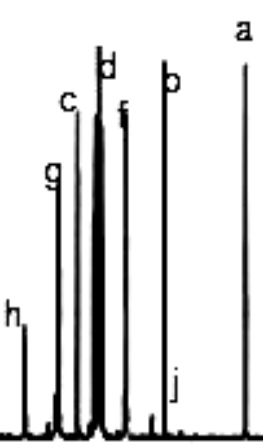

(c)
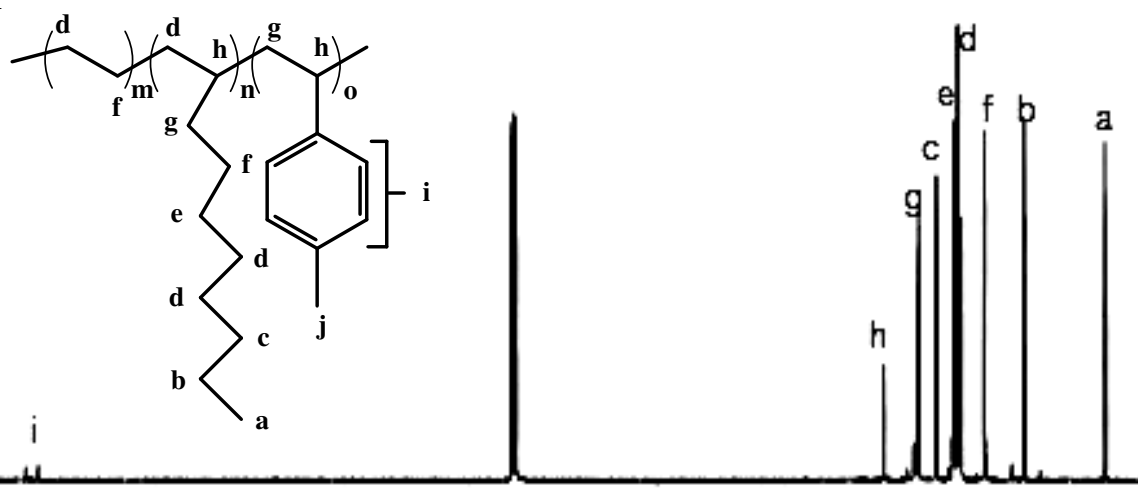

(b)
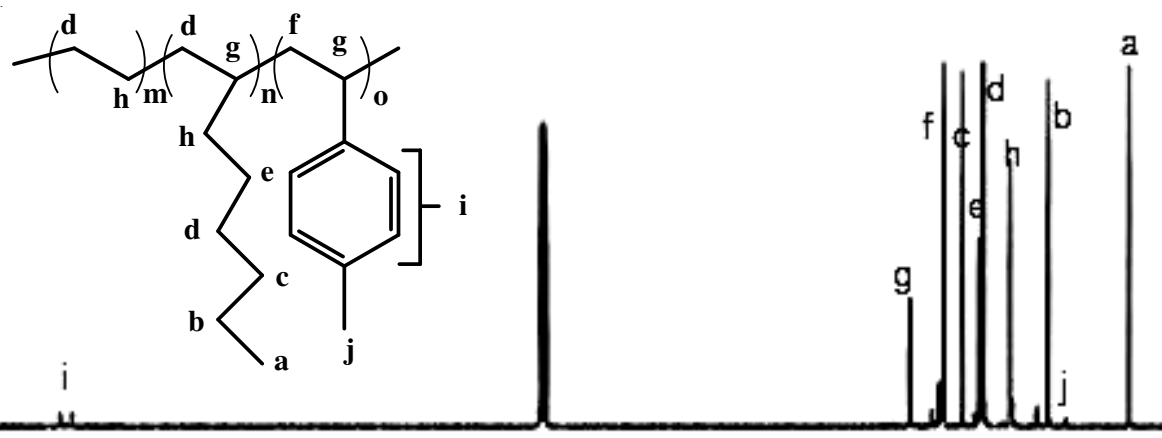

(a)
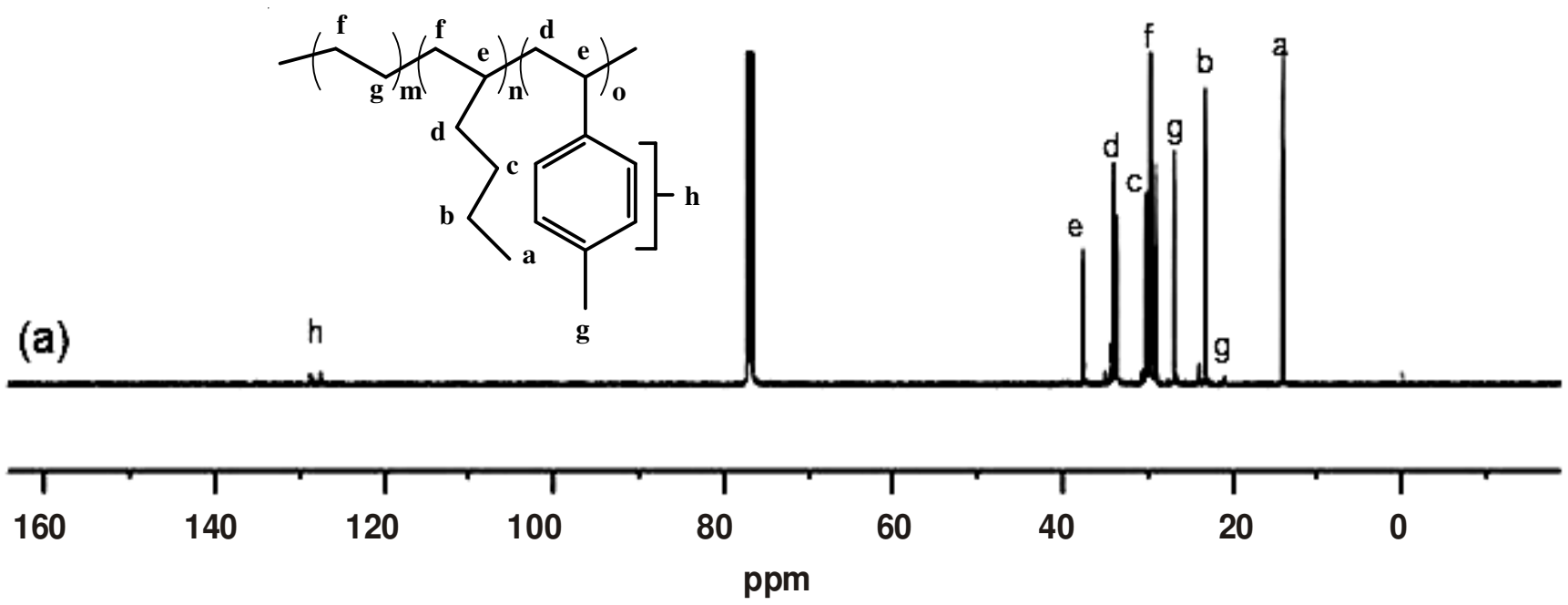

Fig. 3. ${ }^{13} \mathrm{C}$ NMR spectra of the terpolymers: (a) PEHM, (b) PEOM, (c) PEDM and (d) PEDDM 

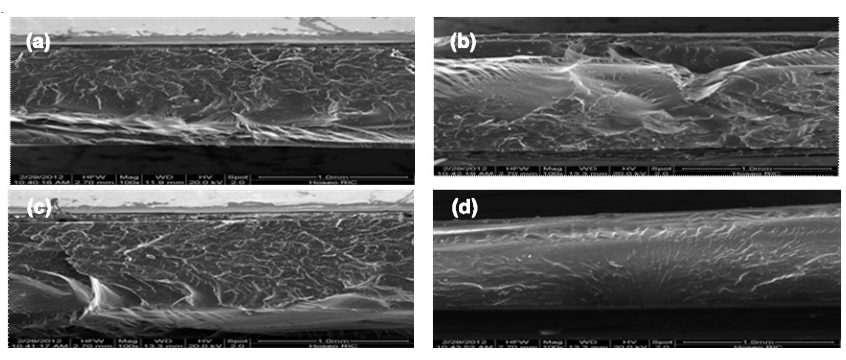

Fig. 4. SEM images of the terpolymers: (a) PEHM, (b) PEOM, (c) PEDM and (d) PEDDM

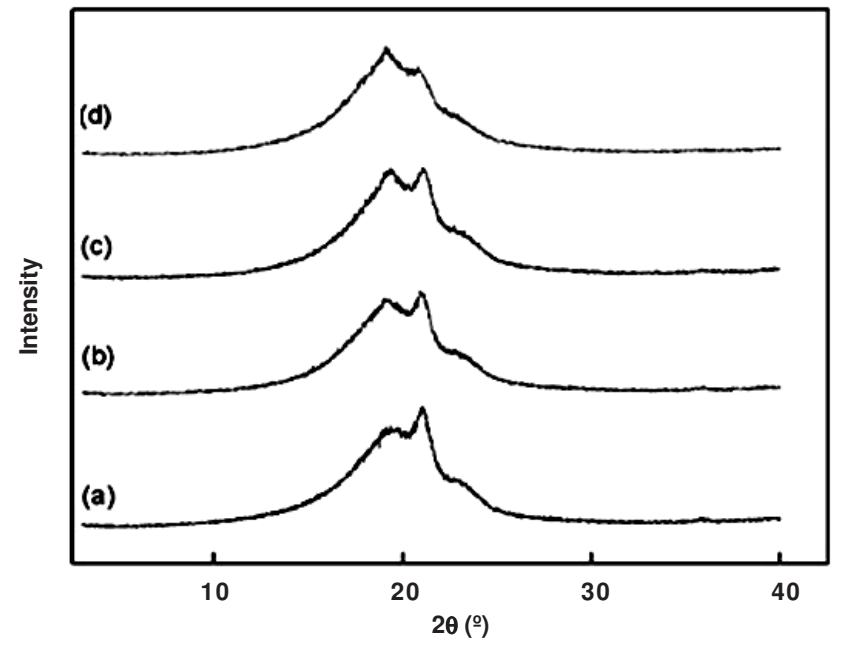

Fig. 5. Wide-angle X-ray scattering data for (a) PEHM, (b) PEOM, (c) PEDM and (d) PEDDM

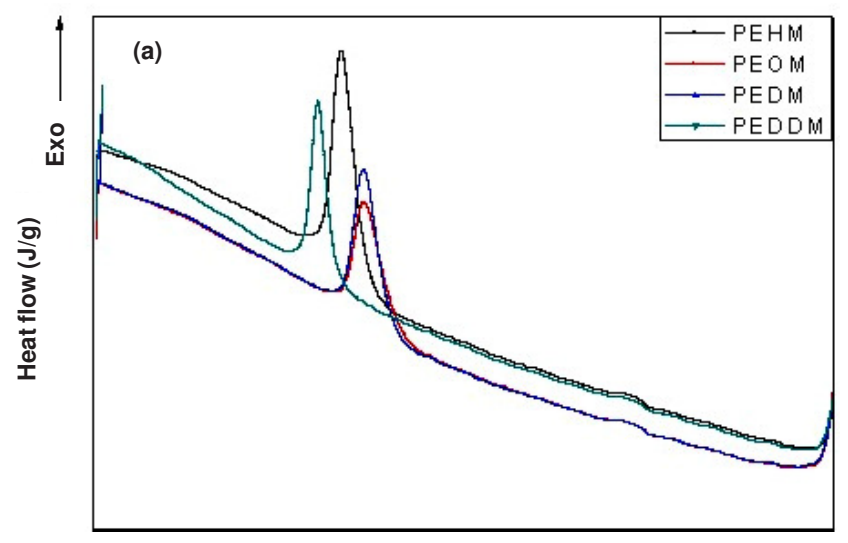

(b)

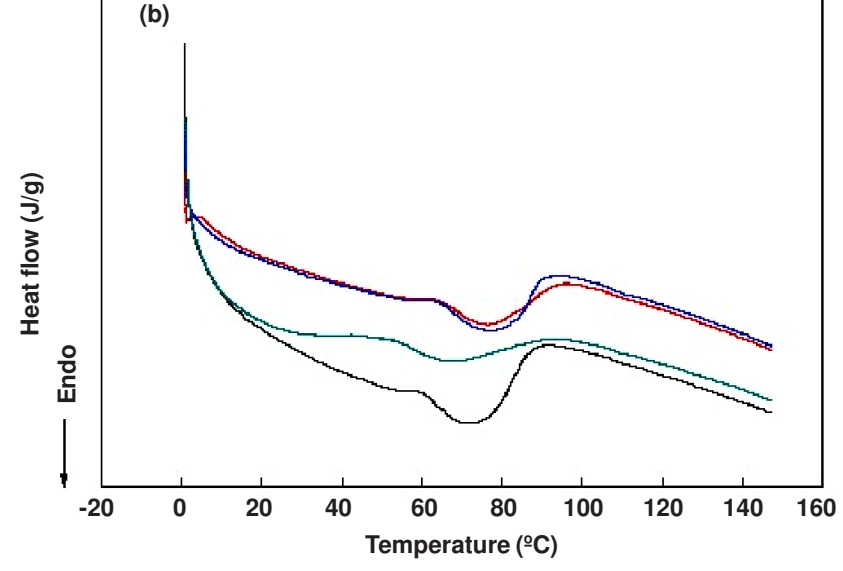

Fig. 6. DSC (a) cooling and (b) melting thermograms of PEHM, PEOM, PEDM and PEDDM
TABLE-2

SUMMARIZATION OF THE DSC DATA OF THE TERPOLYMERS

\begin{tabular}{cccc} 
Name $^{\mathrm{a}}$ & $\mathrm{T}_{\mathrm{m}}{ }^{\mathrm{b}}$ & $\mathrm{T}_{\mathrm{c}}{ }^{\mathrm{b}}$ & $\Delta \mathrm{H}_{\mathrm{m}}{ }^{\mathrm{b}}(\mathrm{g} / \mathrm{J})$ \\
\hline PEHM & 75.80 & 50.50 & 9.174 \\
PEOM & 77.03 & 55.09 & 6.901 \\
PEDM & 80.48 & 55.03 & 7.897 \\
PEDDM & 67.92 & 45.58 & 5.331 \\
\hline
\end{tabular}

${ }^{a}$ Polymerization conditions: ethylene $=0.4 \mathrm{~mol} / \mathrm{L}$, high $\alpha$-olefin $=$ $0.8 \mathrm{~mol} / \mathrm{L}, p-\mathrm{MS}=0.2 \mathrm{~mol} / \mathrm{L}$, catalyst $=2.5 \mu \mathrm{mol},[\mathrm{Al}] /[\mathrm{Zr}]: 1.5,30$ min, $50{ }^{\circ} \mathrm{C}$ and toluene; ${ }^{\mathrm{b}}$ Determined by gel differential scanning calorimetry

The catalytic activities and polymer yield of the terpolymers were higher than those of polyethylene. This was attributed to the positive comonomer effect. Wide angle X-ray scattering data revealed a broad amorphous peak centered at approximately $19.5-20^{\circ}$. The characteristic peaks in the crystalline structure were observed at $21.8^{\circ}$ and $24.3^{\circ}$.

PEDDM with the highest chain length had the lowest $\mathrm{T}_{\mathrm{m}}$ among the terpolymers. This was attributed to the lowest molecular weight and crystallinity of PEDDM compared to those of the other terpolymers.

\section{REFERENCES}

1. T. Garoff, E. Iiskola and P. Sormunen, in eds.: W. Kaminsky and H. Sinn, Transition Metals and Organometallics as Catalysts for Olefin Polymerization, Springer-Verlag, Berlin, p. 200 (1988).

2. M.A. Villar and M.L. Ferreira, J. Polym. Sci., Part A, 39, 1136 (2001).

3. F. Fernanda, E. Nunes and B.G. Griselda, J. Polym. Sci., Part A, 42, 2474 (2004).

4. G.B. Galland, F.F.N. Escher, L.F. da Silva, M.M.D. Forte and R. Quijada, J. Appl. Polym. Sci., 104, 3827 (2007).

5. T.C. Chung and H.L. Lu, J. Polym. Sci, Part A, 36, 1017 (1998).

6. P. Shinjoon, W. Wen-Jun and Z. Shiping, Macromol. Chem. Phys., 201, 2203 (2000).

7. W.-J. Wang, E. Kolodka, S. Zhu and A.E. Hamielec, J. Polym. Sci., Part A, 37, 2949 (1999).

8. N. Naofumi and I.A. Yukio, Macromol. Chem. Phys., 203, 2155 (2002).

9. I. Kim, React. Funct. Polym., 49, 197 (2001).

10. N. Kotohiro, F. Hiroya, K. Shohei, M. Fujiki, H.J. Kim, D.H. Kim and S. Irfan, Macromolecules, 44, 1986 (2011).

11. F. Forlini, E. Pinci, I. Tritto, M. Sacchi and F. Piemontesi, Macromol. Chem. Phys., 203, 645 (2002).

12. S. Graef, U.M. Wahner, R. Van and A.J. Sanderson, J. Polym. Sci. Part A, 40, 128 (2002).

13. W. Kaminsky and H. Drogemuller, Makromol. Chem. Rapid. Commun., 11, 89 (1990).

14. M. Wannaborworn, P. Praserthdam and B. Jongsomjit, Molecules, 16, 373 (2011).

15. N. Kotohiro, F. Fukuda, K. Shohei, M. Fujiki, H.J. Kim, D.H. Kim and Z. Shu, J. Cem. Soc., Dalton Trans, 40, 7842 (2011).

16. P.J. Flory and A.J.J. Vrij, Am. Chem. Soc., 85, 3548 (1963).

17. R. Quijada, A. Narvaez, R. Rojas, F.M. Rabagliati, G.B. Galland, R.S. Mauler, R. Benavente, E. Perez, J.M. Perena and A. Bello, Macromol. Chem. Phys., 200, 1306 (1999).

18. E. Pérez, R. Benavente, R. Quijada, A. Narváez and B.G. Galland, J. Polym. Sci., Part B, 38, 1440 (2000).

19. K.T. Li, C.L. Dai and C.W. Kuo, Catal. Commun., 8, 1209 (2007).

20. S. Krimm and A.V. Tobolsky, J. Polym. Sci., 7, 57 (1951). 